\title{
Long-term optical stability of fluorescent solar concentrator plates
}

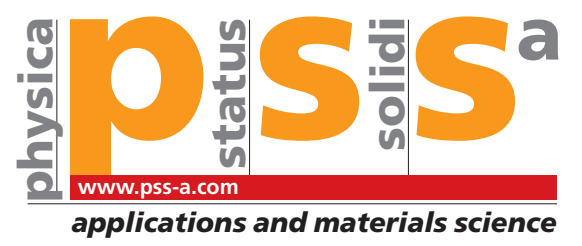

\section{Lenneke H. Slooff ${ }^{\star, 1}$, Nicolaas J. Bakker ${ }^{2}$, Paul M. Sommeling' ${ }^{1}$, Andreas Büchtemann ${ }^{3}$, Armin Wedel ${ }^{3}$, and Wilfried G. J. H. M. van Sark ${ }^{4}$}

\author{
${ }^{1}$ Energy Research Centre of the Netherlands, PO Box 1, 1755ZG Petten, The Netherlands \\ ${ }^{2}$ Energy Research Centre of the Netherlands, High Tech Campus 5 (P-59), 5656AE Eindhoven, The Netherlands \\ ${ }^{3}$ Fraunhofer Institute for Applied Polymer Research, Geiselbergstraße 69, 14476 Potsdam-Golm, Germany \\ ${ }^{4}$ Copernicus Institute of Sustainable Development, Utrecht University, Heidelberglaan 2, 3584CS Utrecht, The Netherlands
}

Received 7 January 2013, revised 15 January 2014, accepted 15 January 2014

Published online 11 February 2014

Keywords fluorescent solar concentrators, optical stability, solar energy

*Corresponding author: e-mail slooff@ecn.nl, Phone: +31 224 564314, Fax: +31 224568214

Fluorescent solar concentrators offer an alternative approach for low-cost photovoltaic energy conversion. For successful application, not only the power conversion efficiency and cost are important, but also lifetime or stability of the devices. As today's concentrator is made of polymer sheets containing organic dyes, which are known to be sensitive to degradation in the presence of light and oxygen, the lifetime under outdoor conditions has been under discussion. This paper shows that depending on the dye and the polymer sheet material, rather stable sheets can be made with $<1 \%$ loss in absorption after 6.5 years outdoor exposure.

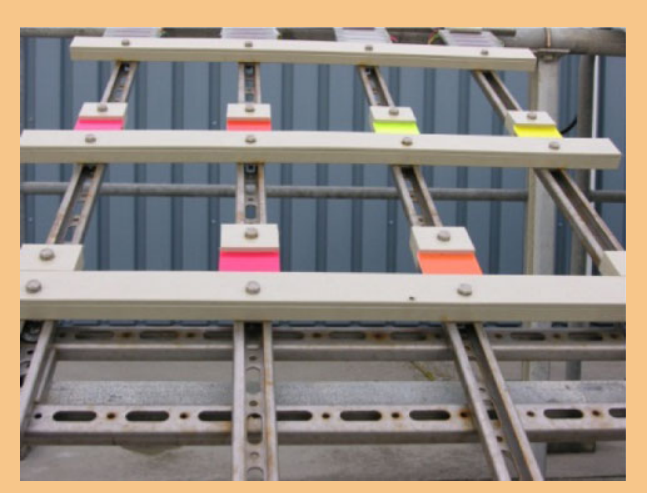

Outdoor roof setup for lifetime testing of fluorescent flat plate concentrators.
1 Introduction The fluorescent solar concentrator (FSC) (also known as the luminescent solar concentrator) has been studied since the late 1970s [1-3]. The concentrator usually consists of a flat polymer plate, doped with luminescent dyes or particles and a solar cell attached to one or more sides, see Fig. 1. The incoming sunlight is absorbed by the luminescent dye or particles, which subsequently randomly emit light at a larger wavelength. Part of this light is trapped by total internal reflection and will reach the solar cell where it is converted into electricity. A fundamental difference of the fluorescent concentrator compared to other concentrator approaches is that it concentrates diffuse light as well as direct light, which makes tracking of the sun unnecessary. This also makes them especially interesting for building integration applications such as facades for office buildings.
Zastrow [4] did extensive research on the FSC and they were one of the first to report on the many aspects of the FSC, like polymer background absorption losses, dye quantum efficiency, and optical quality of the surfaces of the concentrator plate. In the same laboratory, a power conversion efficiency of $4 \%$ was obtained for a stack of two FSCs connected to GaAs cells [5]. Since then the dyes, polymers, and mirrors have been improved substantially. The motivation for studying the FSC, as with any concentrators, is that the cost for power conversion is much lower than for standard solar cells. For this reason several groups reported on the development of FSCs using improved luminescent dyes [6,7], rare-earth complexes [8], and semiconductor quantum dots [9-11]. This has resulted in a world record power conversion efficiency of $7.1 \%[12,13]$. 


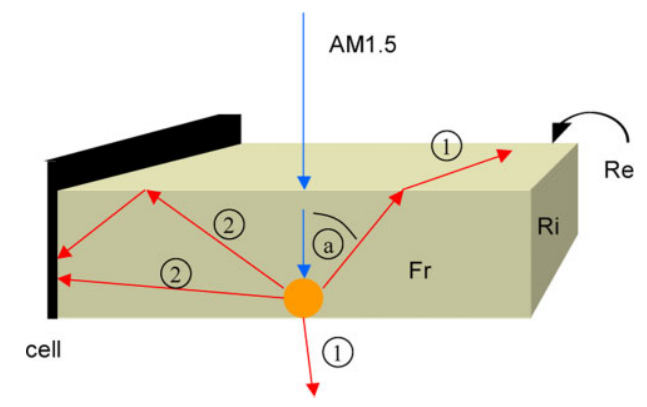

Figure 1 Schematic 3D view of a fluorescent solar concentrator. Light is incident from the top, partly absorbed by a luminescent particle and then randomly emitted at a higher wavelength. Part of the emission falls within the escape cone (determined by the angle (a)) and is lost from the FSC at the surfaces (1). The other part is guided to the solar cell by total internal reflection (2).

Besides the power conversion efficiency, stability is another important aspect for the FSC. There are some manufacturers of polymer sheets that give lifetime numbers. Evonik [14] for example sells clear acrylic sheets plates that have a guaranteed high transmission for over 30 years. No numbers are given for their fluorescent sheets. The Italian company Madreperla mentions numbers of 3-5 years for fluorescent sheets in a private communication and they guarantee high transmission numbers for their transparent sheets for at least 10 years [15]. These numbers are comparable with the best literature values mentioned in FSC applications [16, 17]. The origin of the limited stability depends on the matrix material. We have shown previously that the degradation is due to a combination of light and additives of the polymer matrix as well as remaining monomers in the matrix [18]. Others have reported that the decrease in absorption in poly(methyl methacrylate) (PMMA) FSCs was due to disruption of lateral phenyl rings of the dye [19]. In this paper, we study the stability of FSCs under outdoor conditions.

\section{Experimental}

2.1 Plate fabrication The polymer plates used in this paper were fabricated at the Fraunhofer IAP (FhG-IAP) except from five commercial plates, four from manufacturer $\mathrm{A}$, and one from manufacturer $\mathrm{B}$. As the manufacturers may not be disclosed, we will refer to them as Red A, Red B,
Green B, Orange B, and Yellow B. Details of the plates made at FhG-IAP are given in Table 1. Plexit 55 plates were prepared by polymerizing Plexit 55, which is a honey-like viscous mixture of PMMA and the monomer methylmethacrylate (MMA); the initiator was azoisobutyronitrile (AIBN, $0.01 \%$ ). PMMA plates were prepared by polymerizing distilled MMA. Before distillation the MMA was dried using calciumhydride $\left(30 \mathrm{~min}, 20^{\circ} \mathrm{C}\right)$ and purged with nitrogen. The dried MMA was then distilled at 3 mbar and $5{ }^{\circ} \mathrm{C}$. The distilled MMA was prepolymerized under nitrogen at $95^{\circ} \mathrm{C}$ for 19 min using $0.1 \%$ AIBN as initiator resulting in a high-viscous liquid. For all plates, the luminescent dye was solved in about $2 \mathrm{ml}$ MMA and the solution was added to Plexit 55 or to the distilled and prepolymerized MMA, respectively. The reaction mixtures were then filled into moulds and polymerized using various temperature regimes. For Plexit 55 plates, a temperature program was used which included stepwise increasing the temperature to $70^{\circ} \mathrm{C}$ maximum, then stepwise decreasing temperature down to $22^{\circ} \mathrm{C}$ with the total time of this procedure being $20.5 \mathrm{~h}$. After this, the plates were taken from the mold and treated again at elevated temperatures (up to $120^{\circ} \mathrm{C}$, see Table 1). PMMA plates were prepared by polymerizing the reaction mixture in the mold at the temperatures given in Table 1.

Homogeneous, bubble-free plates were obtained after thermal polymerization.

For the experiments described in this paper, the dyes fluorescence Yellow CRS 040 (CRS040) from Radiant Colour, Lumogen F Red 305 (Red 305), Lumogen F Violet 570 (Violet 570), Lumogen F Yellow 170 (Yellow 170) from BASF, and Pyrromethen 580 (Pyrro 580) from BFI Optilas were used.

2.2 Experimental setup Part of the fluorescent plates have been mounted on the roof of the FhG-IAP building in Potsdam in Germany. The other plates were put on the roof at the ECN office building in Petten in The Netherlands. The plates in Petten are facing almost South (azimuth $174^{\circ}$ ) with a tilt of $30^{\circ}$. In Potsdam, the tilt was $45^{\circ}$ facing South. Absorbance measurement on the plates in Petten were performed using an Hewlett-Packard HP 8453 diode array UV-VIS photospectrometer in the wavelength range 300 $1100 \mathrm{~nm}$. At FhG-IAP, measurements were performed using a Perkin-Elmer Lambda 950 UV/VIS spectrometer.

Table 1 Details of the plates made by Fraunhofer IAP.

\begin{tabular}{lll}
\hline ID & composition & heat treatment \\
\hline ecn538 & dye 0.01\% Pyrromethen 580, Plexit 55 & $24 \mathrm{~h} 80^{\circ} \mathrm{C}+24 \mathrm{~h} 120^{\circ} \mathrm{C}$ \\
ecn577 & dye 0.008\% Yellow 170, Plexit 55 & $24 \mathrm{~h} 80^{\circ} \mathrm{C}+24 \mathrm{~h} 120^{\circ} \mathrm{C}$ \\
ecn653a & dye 0.01\% Red 305, PMMA & $112 \mathrm{~h} 60^{\circ} \mathrm{C}+24 \mathrm{~h} 80^{\circ} \mathrm{C}+24 \mathrm{~h} 120^{\circ} \mathrm{C}$ \\
ecn655b & dye 0.012\% Violet 570, PMMA & $112 \mathrm{~h} 60^{\circ} \mathrm{C}+7.5 \mathrm{~h} 80^{\circ} \mathrm{C}+24 \mathrm{~h} 120^{\circ} \mathrm{C}$ \\
ecn656a & dye 0.0032\% CRS 040, PMMA & $63 \mathrm{~h} 60^{\circ} \mathrm{C}+7.5 \mathrm{~h} 80^{\circ} \mathrm{C}+24 \mathrm{~h} 120^{\circ} \mathrm{C}$ \\
ecn659a & dye $0.009 \%$ Red 305, Plexit 55 & $8 \mathrm{~h} 80^{\circ} \mathrm{C}+24 \mathrm{~h} 120^{\circ} \mathrm{C}$ \\
ecn660b & dye 0.0075\% Red 305, Plexit 55 & $8 \mathrm{~h} 80^{\circ} \mathrm{C}+24 \mathrm{~h} 120^{\circ} \mathrm{C}$ \\
\hline
\end{tabular}


External quantum efficiency (EQE) measurements were carried out using a home-built set-up, consisting of a $1000 \mathrm{~W}$ xenon lamp, 34 band pass interference filters, and four $150 \mathrm{~W}$ halogen lamps for the bias illumination. Measurements with and without bias illumination gave similar results. The reported spectra in this paper are measured without bias illumination. For these measurements, a standard multicrystalline silicon solar cell was attached to the FSC plate using microscope immersion oil with a refractive index of 1.49. After the measurements, the mc-Si solar cell was removed, the FSC's were cleaned and the ageing was continued. The measured $\mathrm{EQE}$ was used to calculate the short circuit current $\left(I_{\mathrm{sc}}\right)$ under AM1.5 conditions.

3 Results Figure 2 shows the absorbance spectra at various times during the ageing of the six plates that were aged on the roof in Petten. As can be seen, Red B, Green B, and Orange $\mathrm{B}$ show a high absorbance. For these plates it is not possible to determine an exact absorbance as the spectrum is very noisy due to saturation of the detector. The error in the absorbance for these plates is roughly $15 \%$ for a relative absorbance of 1 . Although the spectrum changes substantially at the absorption edge of the dye, the overall absorbance of these plates remains high. The other three plates show a lower absorbance with clear absorption bands. As can be seen, Red A is extremely stable. Red 305 shows
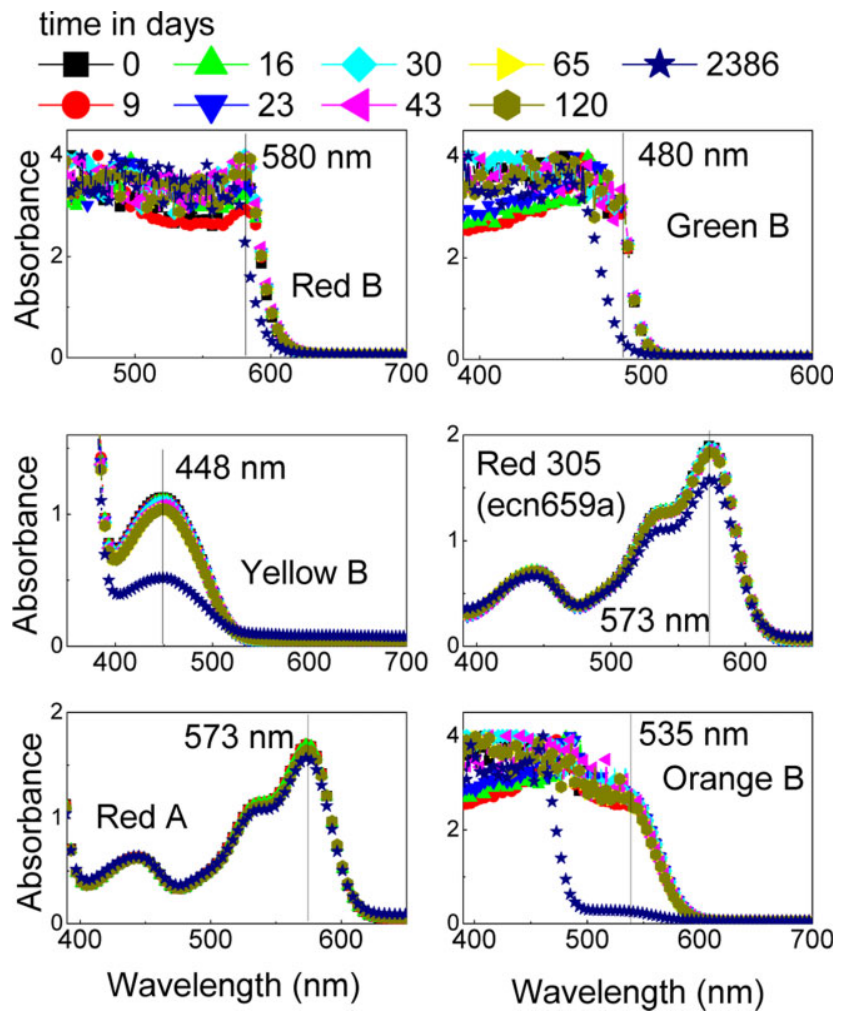

Figure 2 Absorbance spectra for various fluorescent solar concentrator plates measured at different times during the illumination.

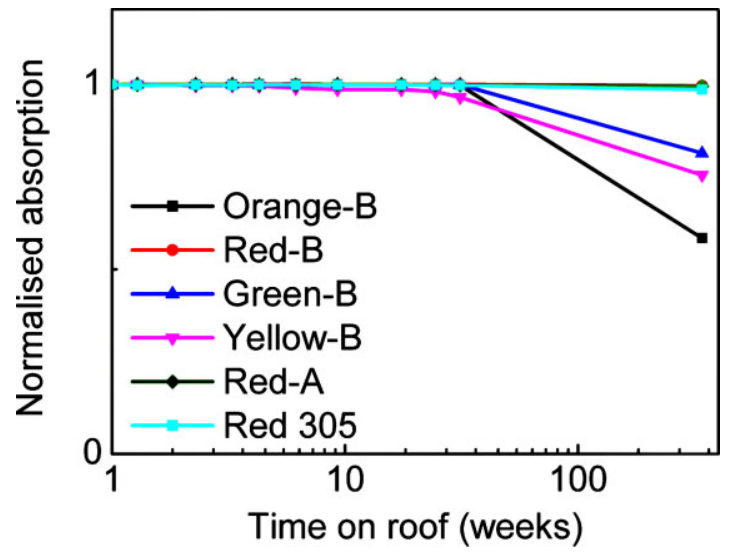

Figure 3 Normalized absorption (normalized to $t=0$ ) as a function of time for several commercial fluorescent solar concentrator plates and one non-commercial plate.

minor ageing, and Yellow B shows substantial ageing. In both Red A and Red 305, only the main absorption peak around $580 \mathrm{~nm}$ is degrading, whereas the peak around $450 \mathrm{~nm}$ is not affected. No additional peaks were observed.

Figure 3 shows the change in the normalized absorption (normalized to $t=0$ ) of the main absorption peak, see vertical lines in the spectra of Fig. 2. It is clear that there is a large spread in stability between the different plates. All three red colored plates, Red B, Red A, and the Red 305 plate made at FhG-IAP are rather stable, but the other colors show a much stronger degradation. Based on the absorption spectrum of the Red A plate, see Fig. 2, it can be assumed that it contains the same Red 305 dye as the plate made by FhG-IAP (ecn659a), which showed to be a very stable dye. The Red B contained a different dye. Wilson and Richards [20] also reported on the good stability of the Red 305 dye, although their results showed a stronger degradation than seen in Fig. 3.

Figure 4 shows the change in the normalized absorption (normalized to $t=0$ ) of the main absorption peak of various

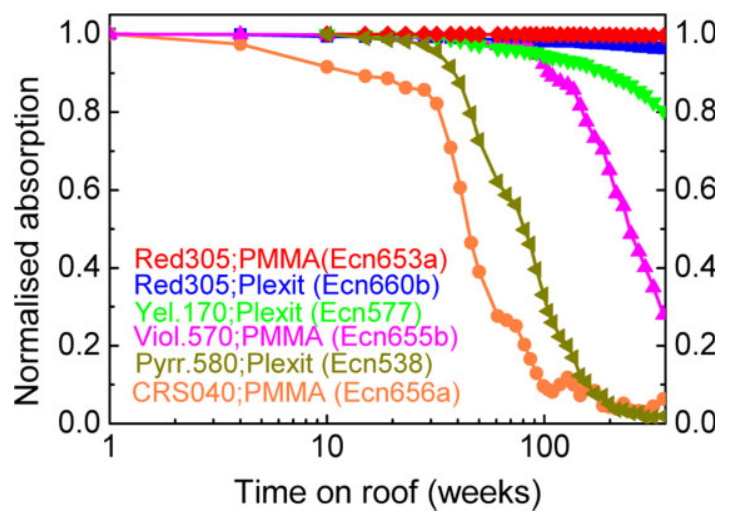

Figure 4 Normalized absorption (normalized to $t=0$ ) as a function of time for various fluorescent solar concentrator plates made at FhG-IAP. 
Table 2 Peak wavelength for absorption.

\begin{tabular}{ll}
\hline plate & wavelength $(\mathrm{nm})$ \\
\hline ECN660b & 574 \\
ECN577 & 503 \\
ECN655b & 376 \\
ECN538 & 520 \\
ECN656a & 439 \\
ECN653a & 574 \\
\hline
\end{tabular}

FSC plates made and tested at Fraunhofer IAP. The absorption was taken at the peak wavelengths as given in Table 2 .

Since the first measurement in August 2006, almost 7 years have passed. It is clear that the CRS040 dye in PMMA and the Pyrromethen 580 dye in Plexit 55, did not survive under the outdoor conditions. Violet 570 in PMMA and Yellow 170 in Plexit 55 perform slightly better, but are still not good enough for use in FSC applications. Again, Red 305 seems to be a very stable dye.

In Plexit 55 a decrease of about $4 \%$ in absorption is observed in almost 6.5 years while in a PMMA plate made using distilled MMA the decrease is only $0.3 \%$. The same trend is seen in Fig. 3 where the Red A, an acrylic sheet, is more stable than the Red 305 in ecn659a, which is a Plexit 55 sheet.

Absorption is the first step in the photovoltaic process and it is thus important that the absorption of the plates is stable. After absorption, the dye emits light at a slightly longer wavelength. This emitted light is guided to the solar cell at the side via total internal reflection. It is thus important
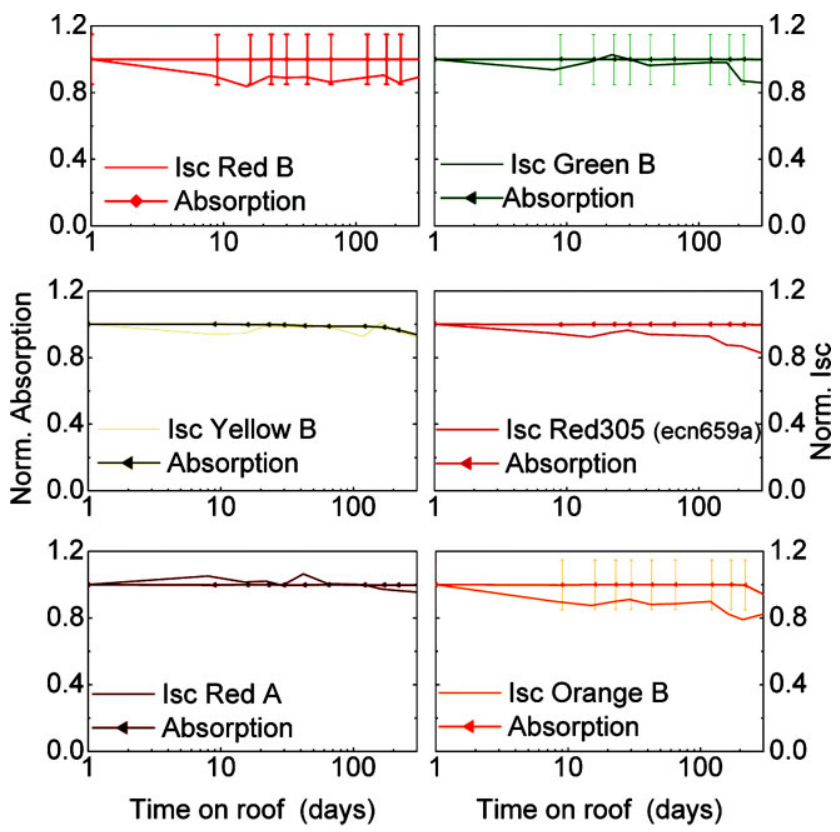

Figure 5 Normalized absorption (1-transmission) and $I_{\mathrm{sc}}$ for FSC plates as a function of time on the roof. that besides a stable absorption, also the emission and outcoupling to the solar cell remains stable. To study this, EQE measurements were performed and from this the short-circuit current $I_{\mathrm{sc}}$ under AM1.5 conditions was calculated, by multiplying the EQE with the AM1.5 spectrum (number of photons per wavelength) and integrating over wavelength.

Figure 5 shows the normalized $I_{\mathrm{sc}}$ together with the normalized absorption (1-transmission) for the plates aged in Petten. Data are shown for the first 200 days. Unfortunately, no EQE data were available after 200 days. For plates Red B, Green B, and Orange B, there is some deviation between the absorption and $I_{\mathrm{sc}}$, but due to the large error in the absorbance values, it is hard to judge if this difference is significant. The general trend in absorption and $I_{\mathrm{sc}}$ seems to be rather similar for these plates. Yellow B and Red A show an excellent agreement between absorption and $I_{\mathrm{sc}}$. For Red 305 (ecn659a) the absorption is very stable, but the $I_{\text {sc }}$ drops much faster. A reference plate, that was kept in the dark, did not show a decrease in $I_{\mathrm{sc}}$.

This suggests that upon illumination the luminescence quantum efficiency of the dye is affected in Plexit 55, but not in the Red A plate. So it is related to the matrix material. The decrease in quantum yield can be explained by a process that generates luminescence quenching sites upon illumination. For Plexit 55 it is known that there are still monomers present after polymerization [17] and that it contains additives like stabilizers that can affect the dye. Unfortunately the suppliers did not reveal more details on the monomer content and the additives to study this in more detail. Figure 6 shows the measured EQE and absorption spectra at the beginning of the experiments and after 218 days for Yellow B and Red 305. Both plates show a high absorption at wavelengths below $400 \mathrm{~nm}$, which is not revealed in the EQE spectra. This absorption is from the polymer matrix and does not result in luminescence that can be trapped and guided to the solar cell at the sight and it thus does not contribute to the current. Furthermore, the shape of absorption and EQE spectra are comparable.

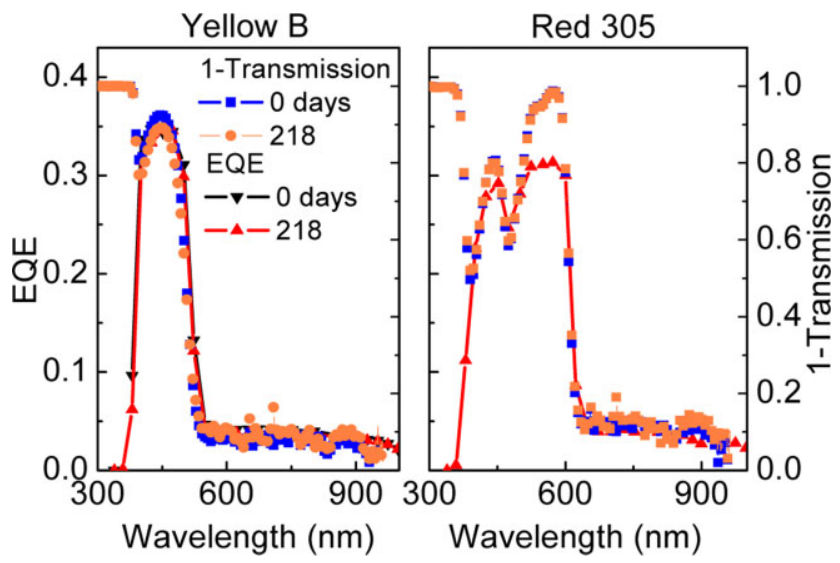

Figure 6 External quantum efficiency (EQE) and absorption (1-transmission) spectra for Yellow B and Red 305 at $t=0$ and $t=218$ days. 
Only for the Red 305 the relative peak height of the two absorption peaks is slightly different in the EQE spectrum. This might be due to a different matrix absorption at these two wavelengths. As the light for the EQE spectrum has to travel through the plate to the edge, a slightly higher matrix absorption can result in a relative lower EQE peak. The absorption spectrum of Red 305 hardly changes in time but the EQE spectrum shows a clear drop.

4 Conclusions Stability measurements of various polymer sheets for use in fluorescent concentrators are shown. The stability is strongly dependent on the specific fluorescent dye used and the matrix material. From the dyes tested, the red dyes are the most stable ones. The BASF Lumogen F Red 305 dye is clearly outperforming the other dyes. For the matrix material, it is found that the commercial acrylic plates and the plate from distilled PMMA perform better than Plexit 55. The results indicate that the matrix influences not only the decrease in absorption, but also the decrease in quantum yield of the dye. The best plate, showed $<1 \%$ decrease in absorption over more than 6.5 years. These results show that some fluorescent plate materials can be used under outdoor conditions with only minor absorptions losses and good FSC output, thereby making them excellent candidates for use in FSCs as is corroborated by $I_{\mathrm{sc}}$ measurements.

Acknowledgements This work has been supported in part by European Commission as part of the Framework 6 integrated project FULLSPECTRUM (contract SES6-CT-2003-502620).

\section{References}

[1] W. Weber and J. Lambe, Appl. Opt. 15, 2299 (1976).

[2] C. F. Rapp and N. L. Boling, Proc. 13th IEEE Photovoltaic Specialists Conference, Washington D.C., USA 1978 (IEEE, New York, 1978), pp. 690-693.

[3] A. Goetzberger and W. Greubel, Appl. Phys. 14, 123 (1977).

[4] A. Zastrow, Physikalische Analyse der Energieverlustmechanismen im Fluoresenzkollektor, Thesis, Freiburg (1981).
[5] A. Goetzberger, W. Stahl, and V. Wittwer, Proc. 6th European Photovoltaic Solar Energy Conference, London, UK, 1985 (Reidel, Dordrecht, 1985), pp. 209-215.

[6] A. F. Mansour, M. G. Al-Shaarawy, S. M. Al-Bashir, M. K. El-Mansy, and M. Hamman, Polym. Int. 51, 393 (2002).

[7] A. A. Earp, G. B. Smith, J. Franklin, and P. Swift, Sol. Energy Mater. Sol. Cells 84, 411 (2004).

[8] K. Machida, H. Li, D. Ueda, S. Inoue, and G. Adachi, J. Lumin. 87-89, 1257, (2000).

[9] K. W. J. Barnham, J. L. Marques, J. Hassard, and P. O'Brien, Appl. Phys. Lett. 76, 1197 (2000).

[10] A. J. Chatten, K. W. J. Barnham, B. F. Buxton, N. J. EkinsDaukes, and M. A. Malik, Proc. 19th European Photovoltaic Solar Energy Conference, Paris, France 2004 (WIP-Munich, ETA-Florence, 2004), pp. 109-112.

[11] Z. Krumer, S. J. Pera, R. J. A. van Dijk-Moes, Y. Zhao, A. F. P. de Brouwer, E. Groeneveld, W. G. J. H. M. vanSark, R. E. I. Schropp, and C. de Mello-Donega, Sol. Energy Mater. Sol. Cells 111, 57 (2013).

[12] L. H. Slooff, E. E. Bende, A. R. Burgers, T. Budel, M. Pravettoni, R. P. Kenny, E. D. Dunlop, and A. Büchtemann, Phys. Status Solidi RRL 2, 257 (2008).

[13] W. G. J. H. M. van Sark, K. W. J. Barnham, L. H. Slooff, A. J. Chatten, A. Büchtemann, A. Meyer, S. J. McCormack, R. Koole, D. J. Farrell, R. Bose, E. E. Bende, A. R. Burgers, T. Budel, J. Quilitz, M. Kennedy, T. Meyer, C. De Mello Donegá, A. Meijerink, and D. Vanmaekelbergh, Opt. Express 16, 21773 (2008).

[14] www.Evonik.com.

[15] http://www.madreperlaspa.com.

[16] G. Seybold and G. Wagenblast, Dyes Pigm. 11, 303 (1989).

[17] A. Zastrow, H. R. Wilson, K. Heidler, V. Wittwer, and A. Goetzberger, 5th E.C. Photovoltic Solar Energy Conf., Athens, Greece 1983 (D. Reidel, Dordrecht, 1984), pp. 202206.

[18] R. Kinderman, L. H. Slooff, A. R. Burgers, N. J. Bakker, A. Büchtemann, R. Danz, and J. A. M. vanRoosmalen, J. Sol. Energy Eng. 129, 277 (2007).

[19] G. Griffini, L. Brambilla, M. Levi, M. Del Zoppo, and S. Turri, Sol. Energy Mater. Sol. Cells 111, 41 (2013).

[20] L. R. Wilson and B. S. Richards, 23rd EU-PVSEC (Valencia, Spain, 2008), pp. 510-512. 